\title{
The oxygen-independent coproporphyrinogen III oxidase HemN utilizes harderoporphyrinogen as a reaction intermediate during conversion of coproporphyrinogen III to protoporphyrinogen IX
}

\author{
Katrin Rand ${ }^{1}$, Claudia Noll ${ }^{2}$, Hans Martin Schiebel ${ }^{3}$, \\ Dorit Kemken $^{4}$, Thomas Dülcks ${ }^{4}$, Markus Kalesse ${ }^{2}$, \\ Dirk W. Heinz ${ }^{1}$ and Gunhild Layer ${ }^{5, *}$ \\ ${ }^{1}$ Division of Structural Biology, Helmholtz Center for \\ Infection Research, Inhoffenstrasse 7, D-38124 \\ Braunschweig, Germany \\ ${ }^{2}$ Institute of Organic Chemistry, Leibniz University \\ Hannover, Schneiderberg 1b, D-30167 Hannover, Germany \\ ${ }^{3}$ Institute of Organic Chemistry, Technical University \\ Braunschweig, Hagenring 30, D-38106 Braunschweig, \\ Germany \\ ${ }^{4}$ Institute of Organic Chemistry, University of Bremen, \\ Leobener Strasse, NW2, D-28359 Bremen, Germany \\ ${ }^{5}$ Institute of Microbiology, Technical University \\ Braunschweig, Spielmannstrasse 7, D-38106 Braunschweig, \\ Germany \\ * Corresponding author \\ e-mail: g.layer@tu-bs.de
}

\begin{abstract}
During heme biosynthesis the oxygen-independent coproporphyrinogen III oxidase HemN catalyzes the oxidative decarboxylation of the two propionate side chains on rings $\mathrm{A}$ and $\mathrm{B}$ of coproporphyrinogen III to the corresponding vinyl groups to yield protoporphyrinogen IX. Here, the sequence of the two decarboxylation steps during HemN catalysis was investigated. A reaction intermediate of $\mathrm{HemN}$ activity was isolated by HPLC analysis and identified as monovinyltripropionic acid porphyrin by mass spectrometry. This monovinylic reaction intermediate exhibited identical chromatographic behavior during HPLC analysis as harderoporphyrin (3-vinyl-8,13,17-tripropionic acid-2,7,12,18tetramethylporphyrin). Furthermore, HemN was able to utilize chemically synthesized harderoporphyrinogen as substrate and converted it to protoporphyrinogen IX. These results suggest that during $\mathrm{HemN}$ catalysis the propionate side chain of ring A of coproporphyrinogen III is decarboxylated prior to that of ring $\mathrm{B}$.
\end{abstract}

Keywords: Escherichia coli; heme biosynthesis; oxidative decarboxylation.

\section{Introduction}

Biosynthesis of hemes and (bacterio)chlorophylls requires the conversion of coproporphyrinogen III to protoporphyrinogen IX. During this reaction the propionate side chains on pyrrole rings $\mathrm{A}$ and $\mathrm{B}$ of coproporphyrinogen III are oxidatively decarboxylated to the corresponding vinyl groups of protoporphyrinogen IX. Two molecules of $\mathrm{CO}_{2}$ are released during the reaction and a final electron acceptor is required to take up two electrons from each side chain (Figure 1). The overall reaction is catalyzed by coproporphyrinogen III oxidases (CPOs). There are two completely unrelated types of $\mathrm{CPO}$ in nature. In eukaryotes and some bacteria, oxidative decarboxylation of coproporphyrinogen III is performed by the oxygen-dependent CPO HemF. In most bacteria, however, the reaction is catalyzed by the oxygen-independent enzyme HemN (Heinemann et al., 2008).

HemF uses molecular oxygen as a final electron acceptor (Breckau et al., 2003). Early studies of the oxidative decarboxylation of coproporphyrinogen III using radioactively labeled substrates revealed that in the oxygen-dependent reaction the propionate group on ring $\mathrm{A}$ is decarboxylated prior to that on ring $\mathrm{B}$, resulting in the intermediate harderoporphyrinogen (3-vinyl-8,13,17-tripropionic acid-2,7,12, 18-tetramethylporphyrinogen) (Sano and Granick, 1961; Cavaleiro et al., 1973, 1974; Games et al., 1976; Elder et al., 1978). Accordingly, exchanges of certain amino acid residues probably involved in the second decarboxylation reaction during HemF catalysis lead to accumulation of harderoporphyrin, the oxidized form of the reaction intermediate harderoporphyrinogen (Schmitt et al., 2005). This was first observed in patients suffering from a rare variant form of hereditary coproporphyria, so-called harderoporphyria (Nordmann et al., 1983).

The oxygen-independent $\mathrm{CPO} \mathrm{HemN}$ belongs to the family of radical SAM enzymes (Sofia et al., 2001). It catalyzes the oxidative decarboxylation of coproporphyrinogen III via a catalytic mechanism completely different to that of HemF. $\mathrm{HemF}$ and $\mathrm{HemN}$ are also structurally completely unrelated. $\mathrm{HemN}$ contains a catalytically essential [4Fe-4S] cluster that transfers an electron to bound $S$-adenosyl-L-methionine (SAM), thereby producing methionine and a 5 -desoxyadenosyl radical (Layer et al., 2002, 2005). This radical then abstracts a hydrogen atom from the $\beta$-carbon of the substrate propionate side chain, resulting in the formation of a coproporphyrinogenyl radical (Layer et al., 2006). Finally, decarboxylation and transfer of the remaining single electron to 


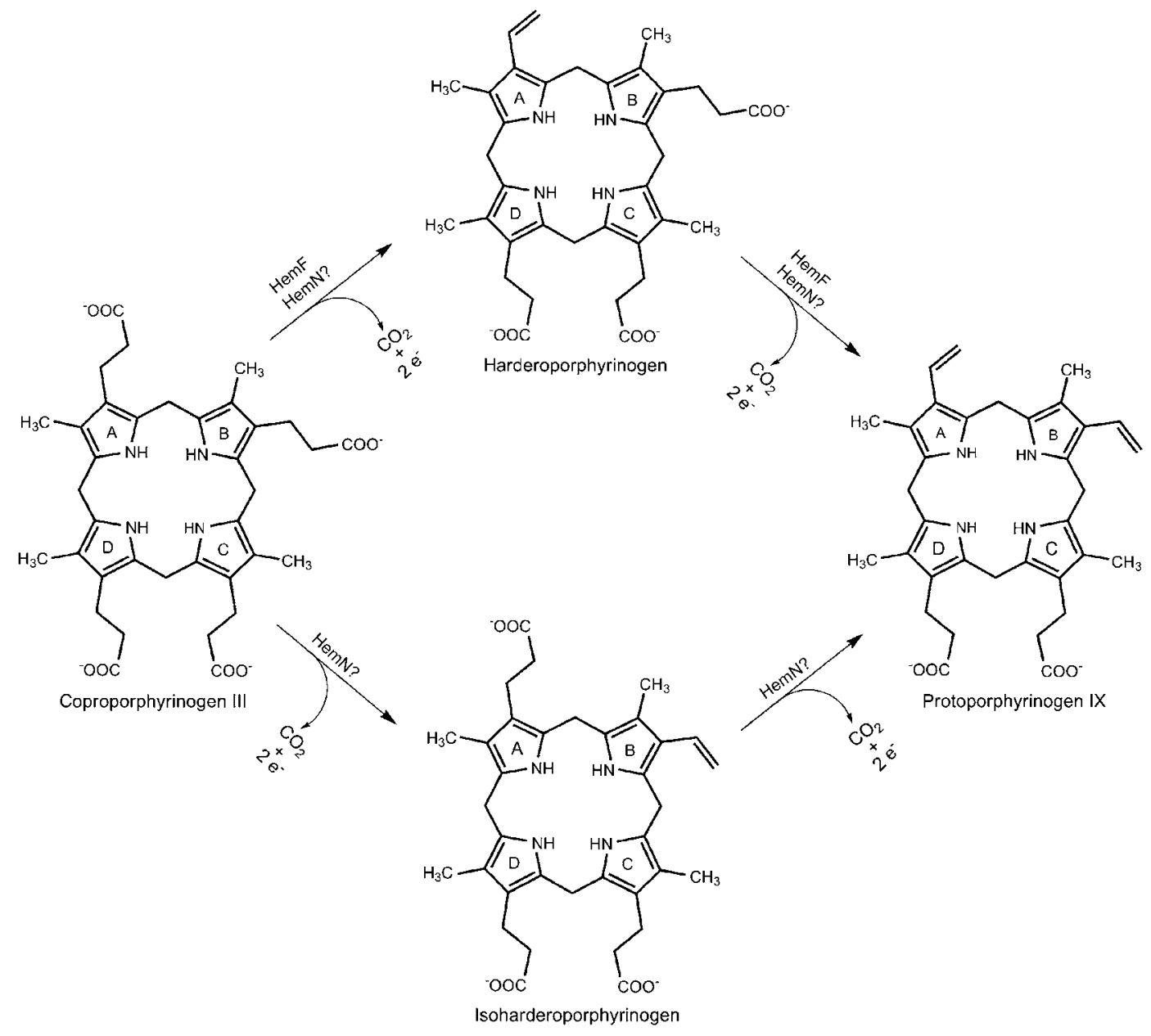

Figure 1 Conversion of coproporphyrinogen III to protoporphyrinogen IX catalyzed by coproporphyrinogen III oxidases (CPOs). CPOs catalyze the oxidative decarboxylation of the propionate side chains on rings A and B of coproporphyrinogen III to the corresponding vinyl side chains of protoporphyrinogen IX. The oxygen-dependent CPO HemF catalyzes this reaction via the monovinylic intermediate harderoporphyrinogen. For the oxygen-independent $\mathrm{CPO} \mathrm{HemN}$, the sequence of the two decarboxylation reactions has not been studied so far.

an as yet unidentified final electron acceptor yields the vinyl group of the reaction product. The crystal structure of Escherichia coli $\mathrm{HemN}$ has been solved, albeit without a bound substrate or product (Layer et al., 2003). Although the oxidized form of the substrate coproporphyrinogen III could be placed manually into the active site pocket of $\mathrm{HemN}$, it was not possible to exclude one or the other orientation of the substrate to predict the sequence of the two decarboxylation reactions. So far, there are no biochemical reports on the sequence of the decarboxylation reactions during oxygenindependent protoporphyrinogen IX formation. Considering that HemF and HemN are two structurally and catalytically unrelated enzymes, both possible reaction intermediates, harderoporphyrinogen and isoharderoporphyrinogen, are conceivable for the HemN-catalyzed reaction.

In this study we address the question of the sequence of the decarboxylation reactions during oxygen-independent decarboxylation of coproporphyrinogen III. We show that a monovinyl-tripropionic acid porphyrin is detectable during the HemN-catalyzed reaction. Furthermore, we show that HemN can utilize chemically synthesized harderoporphyrinogen as a substrate and converts it to protoporphyrinogen IX. These results suggest that HemN, analogously to HemF, catalyzes the conversion of coproporphyrinogen III to protoporphyrinogen IX via the reaction intermediate harderoporphyrinogen.

\section{Results and discussion}

\section{A monovinyl-tripropionic acid porphyrinogen is formed during Hem $\mathrm{N}$ catalysis}

To investigate the sequence of the two decarboxylation reactions catalyzed by $\mathrm{HemN}$, we performed HemN activity assays and analyzed the porphyrin content in the reaction mixtures after 15, 30, 45, 60 and $90 \mathrm{~min}$ of incubation by HPLC. Porphyrins were detected fluorimetrically with exci- 
A
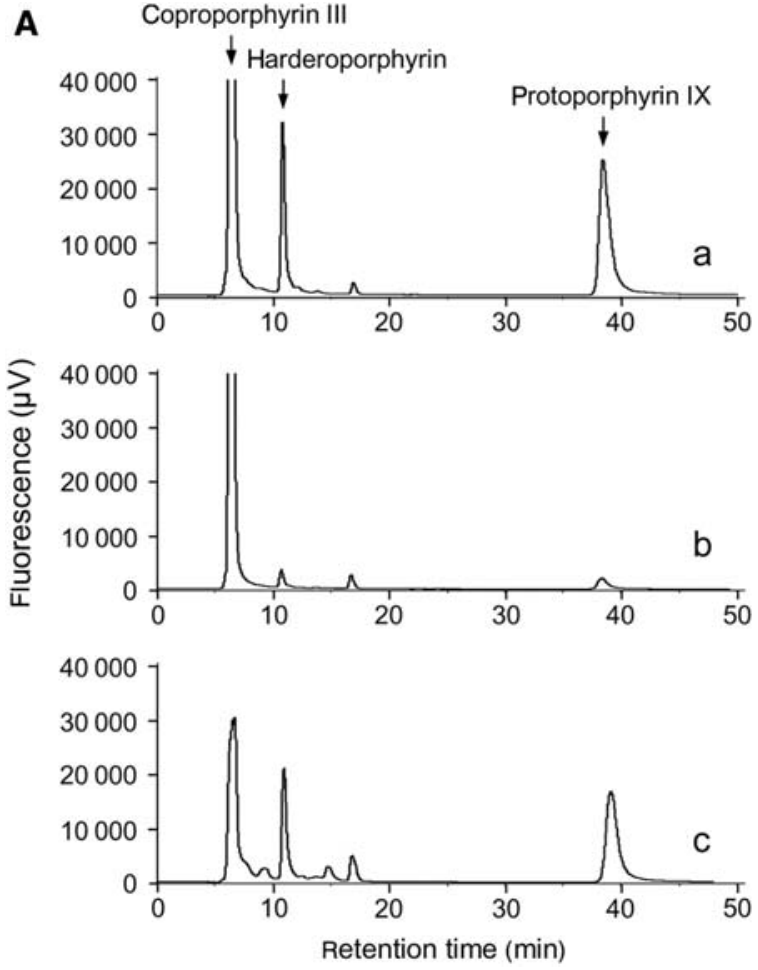

B

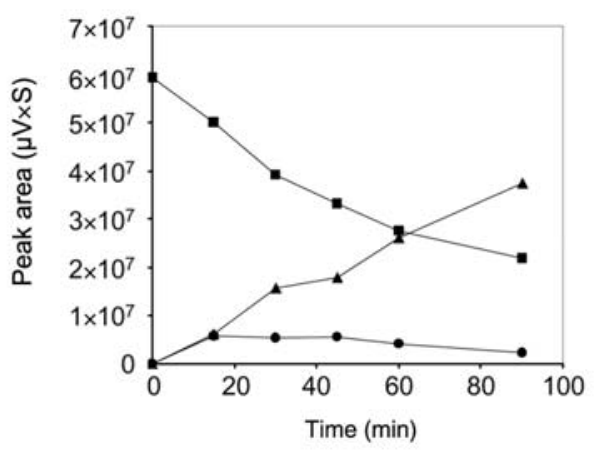

C

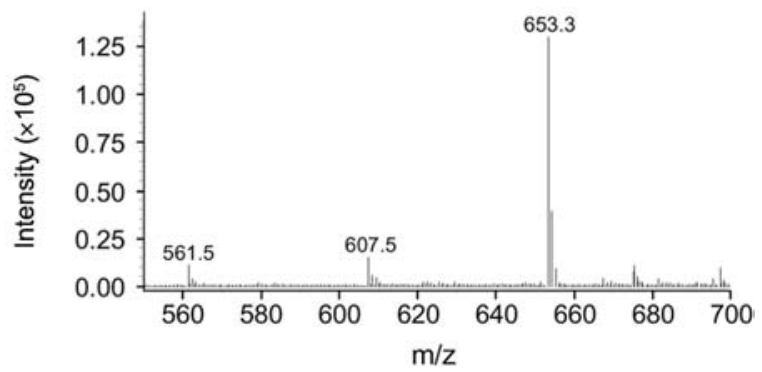

Figure 2 (A) HPLC analysis of HemN and HemF R401K activity assays, (B) time-dependent formation of HemN reaction products, and (C) ESI-MS analysis of porphyrins produced in the HemN activity assay.

(A) HemN and HemF R401K activity assays were performed as described in the text. Reactions were stopped after 30 min of incubation and porphyrinogens were oxidized to the corresponding porphyrins for HPLC analysis. Chromatogram (a) shows the standard HemN activity assay, chromatogram (b) the same activity assay without HemN and chromatogram (c) the HemF R401K activity assay. Retention times for the different porphyrins were $6.6 \mathrm{~min}$ for coproporphyrin III, $39 \mathrm{~min}$ for protoporphyrin IX and $10.8 \mathrm{~min}$ for harderoporphyrin. Coproporphyrin III (Frontier Scientific Europe) and protoporphyrin IX (Sigma) were used as HPLC standards. Porphyrins were detected by fluorescence (excitation at $409 \mathrm{~nm}$, emission at $630 \mathrm{~nm}$ ). (B) Porphyrins present in HemN activity assays after 15, 30, 45, 60 and $90 \mathrm{~min}$ of incubation were analyzed by HPLC. The area $[\mu \mathrm{V} \times \mathrm{s}]$ for peaks corresponding to coproporphyrin III ( $\mathbf{\square})$, protoporphyrin IX $(\mathbf{\Delta})$ and the monovinyl-tripropionic acid porphyrin (-) was plotted against the reaction time. (C) Porphyrins present in a HemN activity assay after $60 \mathrm{~min}$ of incubation were analyzed by electrospray mass spectrometry (ESI-MS). Mass spectra were recorded in negative ion mode. ESIMS analysis revealed the presence of coproporphyrin III with a mass of 653.3 for the $[\mathrm{M}-\mathrm{H}]^{-}$ion, of protoporphyrin IX with a mass of 561.5 and of a monovinyl-tripropionic acid porphyrin with a mass of 607.5.

tation at $409 \mathrm{~nm}$ and emission at $630 \mathrm{~nm}$. Three major peaks were observed in HPLC chromatograms for the standard HemN activity assay (Figure 2A). The oxidized HemN substrate coproporphyrin III eluted at a retention time of $6.6 \mathrm{~min}$, whereas the oxidized HemN product protoporphyrin IX was detected at a retention time of approximately $39 \mathrm{~min}$. In addition to the peaks for these expected porphyrins, a third peak corresponding to a fluorescent molecule was observed at a retention time of $10.8 \mathrm{~min}$. This molecule was identified as porphyrin by photometric diode array analysis. In a control reaction in which $\mathrm{HemN}$ was omitted from the assay mixture, only minor formation of protoporphyrin IX and the additional porphyrin was observed. This residual activity was presumably due to the presence of CPOs in the E. coli cellfree extract necessary for the electron acceptor activity in our assay. In the HemN-containing activity assay, the amounts of the new porphyrin remained almost constant after reaction times of $15,30,45$ and $60 \mathrm{~min}$, whereas the coproporphyrinogen III concentration decreased and the protopor- phyrinogen IX concentration increased (Figure 2B). Since the retention time of this new porphyrin was between those of coproporphyrin III and protoporphyrin IX, we suspected that it was a monovinyl-tripropionic acid porphyrin. This is the oxidized form of a potential HemN reaction intermediate, in which one of the propionate side chains on ring A or B is already decarboxylated to the corresponding vinyl group. To verify this hypothesis, the porphyrins present in a HemN activity assay after $60 \mathrm{~min}$ of incubation were extracted from the reaction mixture and subjected to electrospray mass spectrometry (ESI-MS). Mass spectra were recorded in negative ion mode (Figure 2C). As expected, ESI-MS analysis revealed the presence of coproporphyrin III with a mass of 653.3 for the $[\mathrm{M}-\mathrm{H}]^{-}$ion and of protoporphyrin IX with a mass of 561.5. In addition, a mass of 607.5 was observed, which corresponds to the mass of a monovinyl-tripropionic acid porphyrin.

These results demonstrate that the two propionate side chains on rings $\mathrm{A}$ and $\mathrm{B}$ of coproporphyrinogen III are 
sequentially decarboxylated during the HemN-catalyzed reaction, as is the case for the oxygen-dependent $\mathrm{CPO} \mathrm{HemF}$, and not simultaneously. However, from the experiments described above it was not clear whether the ring A or ring $\mathrm{B}$ propionate side chain was decarboxylated first.

\section{The monovinyl-tripropionic acid porphyrin produced by Hem N shows the same chromatographic behavior as harderoporphyrin produced by HemF}

For the oxygen-dependent CPO HemF it is well established that the ring A propionate side chain is decarboxylated first, resulting in formation of the reaction intermediate harderoporphyrinogen (Sano and Granick, 1961; Cavaleiro et al., 1974, 1973; Games et al., 1976; Elder et al., 1978). Moreover, several HemF mutant proteins have been described for which a single amino acid exchange leads to accumulation of harderoporphyrinogen during activity assays. For example, the human HemF variant R401K is a harderoporphyrinogen-accumulating protein (Schmitt et al., 2005). To obtain a first clue as to whether the monovinyl-tripropionic acid porphyrin produced in HemN activity assays is harderoporphyrin, we compared the chromatographic behavior of the porphyrin produced by HemN and harderoporphyrin produced by HemF R401K using reverse-phase HPLC. We produced the recombinant human HemF mutant protein R401K in $E$. coli and purified the protein as a GST fusion protein. We performed activity assays with HemF R401K, analyzed the porphyrin content of the enzyme reactions by HPLC and compared the chromatograms obtained for HemF R401K and HemN activity assays. As expected, three major peaks in HPLC chromatograms of HemF R401K activity assays represented coproporphyrin III, protoporphyrin IX and harderoporphyrin (Figure 2A). More importantly, the retention time of harderoporphyrin produced in the HemF R401K activity assay was identical to that of the monovinyl-tripropionic acid porphyrin produced in the HemN activity assay.

This result strongly suggests that the monovinylic HemN reaction intermediate observed is indeed harderoporphyrinogen. However, in the absence of an isoharderoporphyrin HPLC standard we cannot exclude the possibility that both harderoporphyrin and isoharderoporphyrin exhibit identical chromatographic behavior during the HPLC assay we used. Therefore, to substantiate our assumption that HemN catalyzes the decarboxylation of coproporphyrinogen III to protoporphyrinogen IX via the reaction intermediate harderoporphyrinogen, we investigated whether HemN can use chemically synthesized harderoporphyrinogen as a substrate and convert it to protoporphyrinogen IX.

\section{Hem N can convert chemically synthesized harderoporphyrinogen to protoporphyrinogen IX}

Harderoporphyrin trimethyl ester 7 was synthesized by condensation of pyrromethanes $\mathbf{3}$ and $\mathbf{5}$ following a modified MacDonald approach that constructs the tetrapyrrole in a convergent approach from a northern and southern segment (Figure 3) (Arsenault et al., 1960; Carr et al., 1971; Cavaleiro et al., 1973, 1974; Chen et al., 1999; Lash et al., 1999; Lud- wig and Lehr, 2004). A slightly modified protocol was used for condensation of pyrromethanes $\mathbf{3}$ and $\mathbf{5}$ to avoid large amounts of self-condensation product $\mathbf{8}$ of the southern fragment 5. In this step the equivalents of the coupling reagent $p$-toluenesulfonic acid were changed from 7.5 to 5 eq. and the time over which dialdehyde $\mathbf{5}$ was added to dipyrrole $\mathbf{3}$ was changed to $14 \mathrm{~h}$. To investigate whether HemN can accept harderoporphyrinogen as a substrate and convert it to protoporphyrinogen IX, we hydrolyzed harderoporphyrin trimethylester with $\mathrm{HCl}$ and reduced the resulting porphyrin using sodium amalgam. The harderoporphyrinogen solution obtained was analyzed by HPLC. Three peaks were observed in the HPLC chromatogram (Figure 4). The major peak corresponds to harderoporphyrin, with a retention time of $10.8 \mathrm{~min}$. The two additional peaks probably correspond to by-products of hydrolysis and sodium amalgam reduction, at retention times of 9 and $6.5 \mathrm{~min}$. These contaminants were not further investigated; however, it has been reported that by-products are formed during hydrolysis of porphyrins containing a vinyl group in $\mathrm{HCl}$ solution and during sodium amalgam reduction (Falk et al., 1956). Therefore, the substrate solution used for the HemN activity assays consisted of a mixture of harderoporphyrinogen and two porphyrinogens that were not further characterized (Figure 4).

HemN activity assays with harderoporphyrinogen as the substrate were performed as described in the materials and methods section. After oxidation of the reaction products, the porphyrin content of the assay mixtures was analyzed by HPLC (Figure 4). In the assay containing $\mathrm{HemN}$, we observed the formation of protoporphyrinogen IX with a concomitant decrease in harderoporphyrinogen. In a control reaction in which $\mathrm{HemN}$ was omitted from the mixture, only minor protoporphyrinogen IX formation from harderoporphyrinogen was observed. This residual activity originated from CPOs present in the E. coli cell-free extract used for the activity assay and was also observed in activity assays with coproporphyrinogen III as substrate (see above). In another control reaction in which no HemN and no E. coli cell-free extract were present, we did not observe any protoporphyrinogen IX formation. From the HPLC chromatograms in Figure 4 it is evident that HemN can accept harderoporphyrinogen as a substrate and convert it to protoporphyrinogen IX. By contrast, the two contaminating porphyrinogens present in the substrate solution (see above) were not significantly further metabolized by HemN.

These results clearly demonstrate that HemN can convert harderoporphyrinogen to protoporphyrinogen IX. The observations described above strongly suggest that $\mathrm{HemN}$ catalyzes the decarboxylation of the ring A propionate side chain of coproporphyrinogen III prior to the second decarboxylation on ring $\mathrm{B}$ with harderoporphyrinogen as a reaction intermediate, although we cannot completely exclude the possibility that HemN could also accept isoharderoporphyrinogen as a substrate. Co-crystallization of HemN with coproporphyrinogen III would provide the necessary insight into the orientation of the substrate and its propionate side chains in the active site of the enzyme. Considering our findings that harderoporphyrinogen is a possible $\mathrm{HemN}$ reaction 


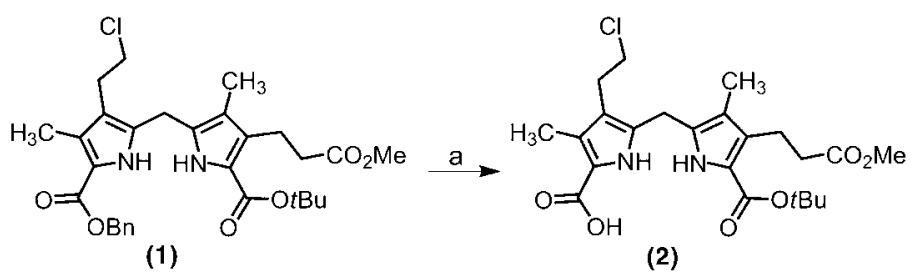<smiles>CCCCOC(=O)c1[nH]c(Cc2[nH]c(C(=O)OC(C)(C)C)c(C)c2CCC(C)(C)C)c(CCOC(C)=O)c1C</smiles>

(4)<smiles>COCCc1c[nH]c(Cc2[nH]cc(C)c2CCCl)c1C</smiles>

(3)<smiles>COC(C)=O</smiles>

(5)

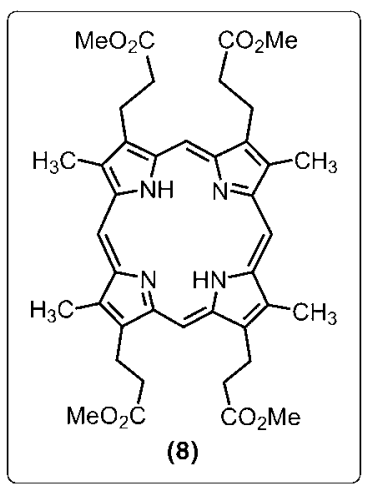

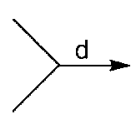

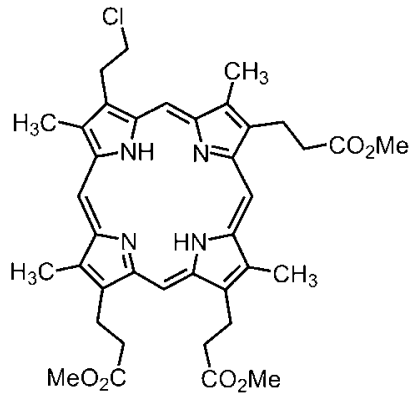

(6)

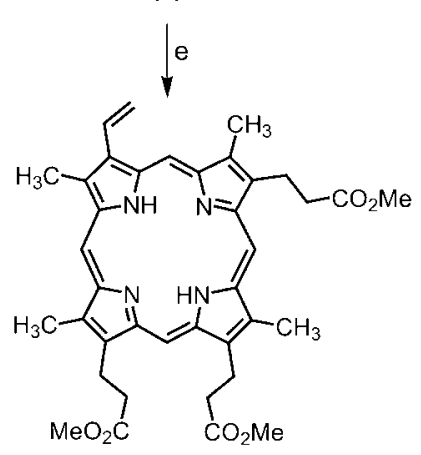

(7)

a: $\mathrm{Pd} / \mathrm{C}, \mathrm{H}_{2}, \mathrm{MeOH}, 20 \mathrm{~h}, 95 \%$

b: TFA, $0^{\circ} \mathrm{C}, 3 \mathrm{~h}, 65 \%$

c: TFA, $\mathrm{CH}(\mathrm{OMe})_{3}, 0^{\circ} \mathrm{C}, 30 \mathrm{~min}, 30 \%$

d: p-toluenesulfonic acid, $\mathrm{CH}_{2} \mathrm{Cl}_{2}, \mathrm{Zn}(\mathrm{OAC})_{2}, 5 \% \mathrm{H}_{2} \mathrm{SO}_{4}, \mathrm{MeOH}, 14 \mathrm{~h}, 36 \%$

e: $\mathrm{KOtBu}, t \mathrm{BuOH}, 5 \% \mathrm{H}_{2} \mathrm{SO}_{4}$, MeOH, $72 \mathrm{~h}, 78 \%$

Figure 3 Synthesis of harderoporphyrin trimethylester.

Harderoporphyrin trimethyl ester (7) was synthesized by condensation of pyrromethanes (3) and (5) following the modified MacDonald approach with some minor modifications as described in the text (Arsenault et al., 1960; Carr et al., 1971; Cavaleiro et al., 1973, 1974; Chen et al., 1999; Lash et al., 1999; Ludwig and Lehr, 2004).

intermediate, the ring A propionate side chain of coproporphyrinogen III is expected to be found in close proximity to the [4Fe-4S]-bound $S$-adenosyl-L-methionine. Further biochemical and crystallographic studies are needed to understand how the reaction intermediate harderoporphyrinogen is further decarboxylated.

\section{Materials and methods}

\section{Chemicals}

Unless otherwise stated, chemicals, reagents and antibiotics were obtained from Sigma-Aldrich (Taufkirchen, Germany) or Merck (Darmstadt, Germany). HPLC-grade methanol, acetonitrile and ammonium acetate were purchased from Fisher Scientific GmbH (Schwerte, Germany). Coproporphyrin III was purchased from Frontier Scientific Europe (Carnforth, UK).

\section{Plasmids, bacteria and growth conditions}

Plasmids for production of recombinant E. coli HemN and recombinant human HemF variant R401K were pET3ahemN (Layer et al., 2002) and pGEX-2T:CPO(R401K) (Schmitt et al., 2005), respectively. E. coli BL21(DE3) or E. coli BL21(DE3) Codon Plus was used as the host for protein production. Growth conditions for recombinant HemN production were as previously described (Layer et al., 2002). For production of recombinant human HemF variant R401K, E. coli BL21(DE3) Codon Plus cells carrying plasmid pGEX-2T:CPO $(R 401 K)$ were grown in LB medium at $37^{\circ} \mathrm{C}$. Gene expression was induced with $50 \mu \mathrm{M}$ isopropyl- $\beta$-D-thiogalactopy- 


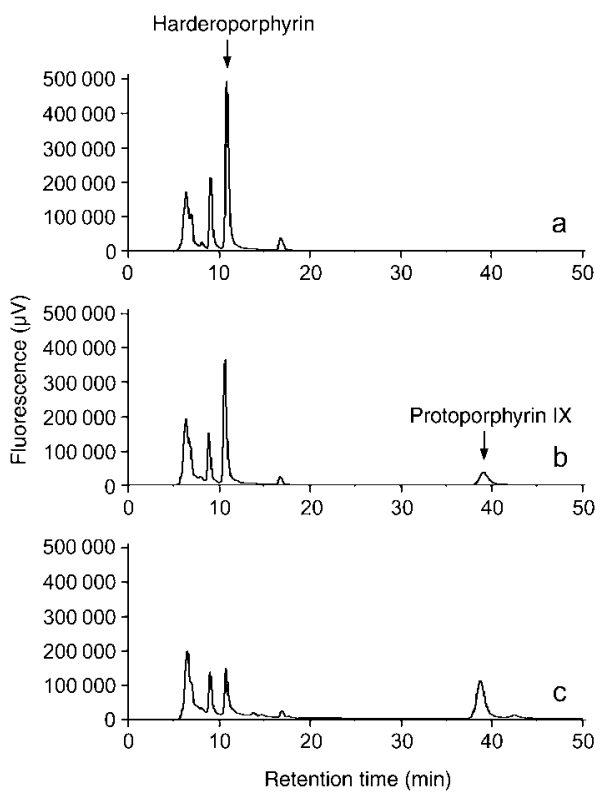

Figure 4 HPLC analysis of HemN activity assays with harderoporphyrinogen as the substrate.

Activity assays with harderoporphyrinogen as the substrate were performed as described in the text. Reactions were stopped after 60 min of incubation and porphyrinogens were oxidized to the corresponding porphyrins. (A) HPLC analysis of porphyrins in a control reaction in which no HemN and no E. coli cell-free extract were present. (B) Analysis of porphyrins in a control reaction with an $E$. coli cell-free extract in the absence of HemN. Only minor protoporphyrinogen IX formation from harderoporphyrinogen was observed. (C) HPLC analysis of porphyrins in a sample containing HemN and E. coli cell-free extract. Formation of protoporphyrin IX (39 $\mathrm{min}$ ) was observed with a concomitant decrease in harderoporphyrin (10.8 min).

ranoside at an $\mathrm{OD}_{600}$ of 0.6 and the cells were further cultivated at $25^{\circ} \mathrm{C}$ overnight to allow recombinant protein production.

\section{Enzyme purification}

Recombinant E. coli HemN was purified as previously described (Layer et al., 2002). Recombinant human HemF variant R401K was purified as a glutathione S-transferase (GST) fusion protein on glutathione-Sepharose (GE Healthcare, München, Germany) according to the manufacturer's instructions. In brief, after protein production E. coli cells were harvested by centrifugation, the cell pellet was resuspended in buffer A [ $50 \mathrm{~mm}$ Tris, $\mathrm{pH} 8.0,100 \mathrm{~mm} \mathrm{NaCl}, 3 \mathrm{~mm}$ dithiothreitol (DTT)] and cells were disrupted by sonication. The soluble protein fraction was incubated with glutathione-Sepharose for $1 \mathrm{~h}$ at $4^{\circ} \mathrm{C}$. The affinity material was then placed in a small column and non-bound proteins were washed off the column with buffer A. The fusion protein GST-HemF R401K was eluted using buffer A supplemented with $10 \mathrm{~mm}$ reduced glutathione. Protein solutions were concentrated by ultrafiltration (Amicon, Millipore $\mathrm{GmbH}$, Eschborn, Germany) and stored at $-20^{\circ} \mathrm{C}$.

\section{Protein concentration}

Bradford reagent (Sigma-Aldrich) was used to determine protein concentrations according to the manufacturer's instructions using bovine serum albumin as a standard.

\section{HemN activity assay}

The HemN activity assay was performed under anaerobic conditions in an anaerobic chamber (Coy Laboratories, Grass Lake, MI, USA) as previously described (Layer et al., 2002). The standard assay mixtures contained $100 \mathrm{~mm}$ Bis-Tris, $\mathrm{pH} 7.0,0.3 \%$ (v/v) Triton X100, $500 \mu \mathrm{M}$ NADH, $500 \mu \mathrm{M}$ SAM, $15 \mu 1$ of $E$. coli cell-free extract (prepared as described by Layer et al., 2002), 3 mм DTT, $300 \mathrm{~mm} \mathrm{NaCl}$ and $20 \mu \mathrm{M}$ coproporphyrinogen III in a total volume of $100 \mu \mathrm{l}$. When coproporphyrinogen III was used as the substrate the final HemN concentration was $1.5 \mu \mathrm{M}$. When chemically synthesized harderoporphyrinogen was used as the substrate the final HemN concentration was $15 \mu \mathrm{M}$. The assay mixtures were incubated at $37^{\circ} \mathrm{C}$. After defined points of time the reactions were stopped by the addition of $5 \mu \mathrm{H}_{2} \mathrm{O}_{2}(30 \%)$. After 15 min of incubation the samples were flash frozen in liquid nitrogen and stored at $-20^{\circ} \mathrm{C}$ until further use.

\section{HemF activity assay}

The HemF activity assay was performed in a total volume of $100 \mu \mathrm{l}$ of $100 \mathrm{~mm}$ Bis-Tris, pH 7.0 containing $0.3 \%$ (v/v) Triton X-100, $3 \mathrm{~mm}$ DTT, $300 \mathrm{~mm} \mathrm{NaCl}$ and $20 \mu \mathrm{M}$ coproporphyrinogen III. The final HemF concentration was $5 \mu \mathrm{M}$. After 30 or $60 \mathrm{~min}$ of incubation at $37^{\circ} \mathrm{C}$ the reaction was stopped by addition of $5 \mu 1$ of $\mathrm{H}_{2} \mathrm{O}_{2}$ $(30 \%)$. After $15 \mathrm{~min}$ of incubation the samples were flash-frozen in liquid nitrogen and stored at $-20^{\circ} \mathrm{C}$ until further use.

\section{Coproporphyrinogen III preparation}

Coproporphyrinogen III was prepared by chemical reduction of coproporphyrin III with $3 \%$ sodium amalgam as previously described (Layer et al., 2002).

\section{Harderoporphyrinogen preparation}

Harderoporphyrinogen was generated by reduction of harderoporphyrin with $3 \%$ sodium amalgam. In brief, harderoporphyrin was dissolved in $250 \mu \mathrm{l}$ of $10 \mathrm{~mm} \mathrm{KOH}$ and heated to $80^{\circ} \mathrm{C}$. Freshly prepared $3 \%$ sodium amalgam $(0.6 \mathrm{~g})$ was added to the hot harderoporphyrin solution and the mixture was stirred for $5 \mathrm{~min}$ in the dark. The almost colorless solution was filtered through glass wool and $550 \mu \mathrm{l}$ of buffer ( $1 \mathrm{~m}$ Tris-HCl, pH 7.5, 5 mm DTT) was added. The solution was adjusted to $\mathrm{pH} 8.0$ by adding several drops of $5 \mathrm{M}$ $\mathrm{HCl}$. The harderoporphyrinogen solution was stored at $-20^{\circ} \mathrm{C}$ until further use.

\section{Harderoporphyrin preparation}

Harderoporphyrin was obtained from harderoporphyrin trimethyl ester by hydrolysis with $5 \mathrm{M} \mathrm{HCl}$ for $6 \mathrm{~h}$ at room temperature. Following hydrolysis, the $\mathrm{pH}$ of the porphyrin solution was adjusted to 4 by adding saturated sodium acetate. The precipitated porphyrin was sedimented by centrifugation and washed with water. The porphyrin sediment was dissolved in $5 \mathrm{ml}$ of diethyl ether and harderoporphyrin was extracted from the ether with $0.15 \mathrm{M} \mathrm{HCl}$. The harderoporphyrin solution obtained was freeze-dried and the porphyrin was stored at $-20^{\circ} \mathrm{C}$ until further use.

\section{Synthesis of harderoporphyrin trimethyl ester}

Harderoporphyrin trimethyl ester (7) was synthesized by condensation of pyrromethanes (3) and (5) (Figure 3) following the mod- 
ified MacDonald approach (Arsenault et al., 1960; Cavaleiro et al., 1974) with some minor modifications. Pyrromethanes (1) and (4) were synthesized as previously described (Carr et al., 1971; Chen et al., 1999; Lash et al., 1999; Ludwig and Lehr, 2004).

tert-Butyl-5' -(carboxyacid)-3',4-bis(2-methoxycarbonylethyl)-3,4'-dimethyl-2,2'-dipyrryl-methane-5-carboxylate (2): Dipyrryl (1) (749 mg, $1.35 \mathrm{mmol}$ ) was dissolved in $\mathrm{MeOH}(80 \mathrm{ml})$ and $10 \%$ palladium on charcoal $(75 \mathrm{mg}$ ) was added. The reaction was stirred at room temperature under a hydrogen atmosphere for $20 \mathrm{~h}$. The catalyst was removed by filtration through a short plug of Celite, which was washed with $\mathrm{MeOH}$. The solvent was removed under reduced pressure to yield 2 as red crystals $(599 \mathrm{mg}, 1.28 \mathrm{mmol}$, $95 \%)$.

Melting point $145-148^{\circ} \mathrm{C} . \quad R_{\mathrm{f}}=0.22\left(\mathrm{CH}_{2} \mathrm{Cl}_{2} / \mathrm{EtOAc} 5: 2\right) .{ }^{1} \mathrm{H}$ NMR (200 MHz, $\mathrm{CDCl}_{3}$ ): $\delta 11.54$ (br s, $\left.1 \mathrm{H}\right), 10.76$ (br s, $\left.1 \mathrm{H}\right), 3.87$ $(\mathrm{s}, 2 \mathrm{H}), 3.66(\mathrm{~s}, 3 \mathrm{H}), 3.38-3.27(\mathrm{~m}, 2 \mathrm{H}), 3.02-2.81(\mathrm{~m}, 4 \mathrm{H})$, 2.55-2.40 (m, 2H), 2.29 (s, 3H), 2.11 (s, 3H), 1.53 (s, 9H). ${ }^{13} \mathrm{C}$ NMR $\left(100 \mathrm{MHz}, \mathrm{CDCl}_{3}\right)$ : $\delta 173.7,166.1,163.3,133.5,131.3$, 129.7, 128.7, 119.2, 118.2, 118.0, 116.3, 82.4, 51.7, 43.9, 35.3, 28.6, 28.5, 22.8, 21.5, 11.0, 9.1. HR-EI-MS: calcd. for $\mathrm{C}_{22} \mathrm{H}_{31} \mathrm{ClN}_{2} \mathrm{O}_{4}$ $[\mathrm{M}-\mathrm{COO}]^{+\cdot} 422.1972$, found 422.1975.

$1 H$-Dipyrrole (3): Trifluoroacetic acid (TFA, $11 \mathrm{ml}$ ) was added to $2(264 \mathrm{mg}, 566 \mu \mathrm{mol})$ at $0^{\circ} \mathrm{C}$ and the solution was stirred for $3 \mathrm{~h}$. The solvent was then evaporated under reduced pressure. The residual oil was dissolved in $\mathrm{CH}_{2} \mathrm{Cl}_{2}(10 \mathrm{ml})$ and washed successively with $\mathrm{H}_{2} \mathrm{O}(5 \mathrm{ml}), \mathrm{NaHCO}_{3}$ (aq.) $(5 \mathrm{ml})$ and $\mathrm{H}_{2} \mathrm{O}(5 \mathrm{ml})$. The organic layer was dried over $\mathrm{Na}_{2} \mathrm{SO}_{4}$ and concentrated and the residue was purified by flash chromatography on silica gel $(100 \%$ EtOAc) to provide $3(123.6 \mathrm{mg}, 382.9 \mu \mathrm{mol}, 68 \%)$.

$R_{\mathrm{f}}=0.60\left(\mathrm{CH}_{2} \mathrm{Cl}_{2} / \mathrm{EtOAc} 10: 1\right) .{ }^{1} \mathrm{H}$ NMR $\left(400 \mathrm{MHz}, \mathrm{CDCl}_{3}\right): \delta$ 8.74 (br s, 1H), 7.69 (br s, 1H), 6.52 (d, $J=2.6 \mathrm{~Hz}, 1 \mathrm{H}), 6.48$ (d, $J=2.6 \mathrm{~Hz}, 1 \mathrm{H}), 3.94$ (s, 2H), 3.67 (s, 3H), 3.49 (t, $J=7.1 \mathrm{~Hz}, 3 \mathrm{H})$, 2.91-2.85 (m, 2H), 2.79-2.73 (m, 2H), 2.59-2.53 (m, 2H), 2.33 (s, $3 \mathrm{H}), 2.04(\mathrm{~s}, 3 \mathrm{H}) .{ }^{13} \mathrm{C}$ NMR (200 MHz, $\left.\mathrm{CDCl}_{3}\right): \delta 174.0,126.5$, 124.7, 122.0, 118.3, 116.0, 115.1, 114.3, 113.4, 51.6, 45.1, 34.9, 28.2, 23.2, 21.2, 10.4, 8.9. HR-EI-MS: calcd. for $\mathrm{C}_{17} \mathrm{H}_{23} \mathrm{ClN}_{2} \mathrm{O}_{2}$ $[M]^{+\cdot} 322.1448$, found 322.1450 .

5,5'-Diformyl-4,4'-dimethyl-3,3'-bis-(methoxycarbonylethyl-2,2'dipyrrylmethane (5): 5,5'-bis(tert-butoxycarbonyl)-4,4'-dimethyl3,3'-bis-(methoxycarbonylethyl)-2,2'-dipyrryl-methane (4) (2.37 g, $4.33 \mathrm{mmol})$ was dissolved in TFA $(13 \mathrm{ml})$ and stirred at $0^{\circ} \mathrm{C}$ for $30 \mathrm{~min}$. Trimethyl orthoformate $(4.13 \mathrm{~g}, 4.27 \mathrm{ml}, 38.98 \mathrm{mmol})$ was added and stirred for an additional $20 \mathrm{~min}$. The mixture was quenched with brine $(60 \mathrm{ml})$ and diluted with ammonia $(10 \%)$ to adjust the $\mathrm{pH}$ to 8 . The organic layer was separated and the aqueous layer was extracted with EtOAc $(5 \times 40 \mathrm{ml})$. The combined organic layers were dried over $\mathrm{Na}_{2} \mathrm{SO}_{4}$, filtered and evaporated under reduced pressure. Purification using flash chromatography $(100 \%$ EtOAc) on silica gel provided aldehyde $5(528 \mathrm{mg}, 1.30 \mathrm{mmol}$, $30 \%$ ) as brown crystals.

Melting point $179-180^{\circ} \mathrm{C} . \quad R_{\mathrm{f}}=0.41 \quad$ (EtOAc). ${ }^{1} \mathrm{H} \quad \mathrm{NMR}$ $\left(400 \mathrm{MHz}, \mathrm{CDCl}_{3}\right) \delta 10.01$ (br s, 2NH), $9.48(\mathrm{~s}, 2 \mathrm{H}), 4.04(\mathrm{~s}, 2 \mathrm{H})$, 3.71 (s, 6H), 2.80 (t, J=7.1 Hz, 4H), 2.55 (t, J=7.1 Hz, 4H), 2.29 (s, 6H). ${ }^{13} \mathrm{C}$ NMR $\left(100 \mathrm{MHz}, \mathrm{CDCl}_{3}\right): \delta 176.9,174.0,138.1,135.2$, 129.2, 121.2, 52.2, 34.3, 22.6, 19.1, 9.0. HR-EI-MS: calcd. for $\mathrm{C}_{21} \mathrm{H}_{26} \mathrm{~N}_{2} \mathrm{O}_{6}[M]^{+\cdot} 402.1791$, found 402.1788 .

2-Chloroethylporphyrin (6): $1 \mathrm{H}$-Dipyrrole (3) $(31.3 \mathrm{mg}$, $97.0 \mu \mathrm{mol})$ was dissolved in $\mathrm{CH}_{2} \mathrm{Cl}_{2}(22 \mathrm{ml})$ and stirred in the dark with $p$ TsOH $(92.2 \mathrm{mg}, 484.8 \mu \mathrm{mol})$. A solution of the dipyrryl (5) (38.6 mg, $95.9 \mu \mathrm{mol})$ in $\mathrm{CH}_{2} \mathrm{Cl}_{2}(10 \mathrm{ml})$ was added dropwise to the reaction mixture over $14 \mathrm{~h}$. After complete addition the resulting dark red solution was stirred at room temperature for $2 \mathrm{~h}$. A saturated solution of zinc acetate in methanol $(1.5 \mathrm{ml})$ was added and the reaction was set aside for $10 \mathrm{~h}$. The mixture was washed with brine $(25 \mathrm{ml}), \mathrm{NaHCO}_{3}$ (aq.) $(25 \mathrm{ml})$, and brine $(25 \mathrm{ml})$, dried over $\mathrm{Na}_{2} \mathrm{SO}_{4}$ and evaporated to dryness. The residue was treated with $5 \% \mathrm{H}_{2} \mathrm{SO}_{4}$ in $\mathrm{MeOH}(20 \mathrm{ml})$ for $14 \mathrm{~h}$ in the dark and then diluted with $\mathrm{CH}_{2} \mathrm{Cl}_{2}(40 \mathrm{ml})$. The organic layer was successively washed with $\mathrm{NaOAc}_{\text {(aq.) }}(15 \mathrm{ml}), \mathrm{NaHCO}_{3}$ (aq.) $(15 \mathrm{ml})$, and brine $(25 \mathrm{ml})$, dried over $\mathrm{Na}_{2} \mathrm{SO}_{4}$, filtered and evaporated. The residue was purified by flash chromatography on silica gel (EtOAc/ $\mathrm{CH}_{2} \mathrm{Cl}_{2}$ 1:6) to give the chloroethylporphyrin $6(22.3 \mathrm{mg}, 32.4 \mu \mathrm{mol}, 33 \%)$ as red crystals.

Melting point $173-174^{\circ} \mathrm{C} . \quad R_{\mathrm{f}}=0.55\left(\mathrm{CH}_{2} \mathrm{Cl} /\right.$ /EtOAc $\left.6: 1\right) .{ }^{1} \mathrm{H}$ NMR (400 MHz, $\left.\mathrm{CDCl}_{3}\right)$ : $\delta 10.00(\mathrm{~s}, 3 \mathrm{H}), 10.02(\mathrm{~s}, 1 \mathrm{H}), 4.56-4.24$ $\left(\mathrm{m}, 6 \mathrm{H}, 3 \times \mathrm{CH}_{2}\right), 3.64(\mathrm{~s}, 9 \mathrm{H}, 3 \times \mathrm{OMe}), 3.31-3.14(\mathrm{~m}, 4 \mathrm{H}$, $\left.2 \times \mathrm{CH}_{2}\right), 2.67-2.49\left(\mathrm{~m}, 2 \mathrm{H}, \mathrm{CH}_{2}\right), 2.43-2.18\left(\mathrm{~m}, 4 \mathrm{H}, 2 \times \mathrm{CH}_{2}\right), 1.20$ $\left(\mathrm{m}, 12 \mathrm{H}, 4 \times \mathrm{CH}_{3}\right),-3.79$ (brs, 2NH). HR-ESI-MS: calcd. for $\mathrm{C}_{38} \mathrm{H}_{44} \mathrm{ClN}_{4} \mathrm{O}_{6}[\mathrm{M}+\mathrm{H}]^{+}$687.2849, found 687.2946.

Harderoporphyrin trimethyl ester (7): Chloroporphyrin (6) (11.8 mg, $17.2 \mu \mathrm{mol})$ was dissolved in $\mathrm{CH}_{2} \mathrm{Cl}_{2}(4.9 \mathrm{ml})$ and treated in the dark with a saturated methanolic $\mathrm{Zn}(\mathrm{OAc})_{2}$ solution $(1.5 \mathrm{ml})$. After $2 \mathrm{~h}$, water $(3 \mathrm{ml})$ was added and the zinc complex was extracted with $\mathrm{CH}_{2} \mathrm{Cl}_{2}$. The organic layer was dried over $\mathrm{Na}_{2} \mathrm{SO}_{4}$ and filtered and the solvent was removed under reduced pressure. The residue was dissolved in tetrahydrofuran $(2.1 \mathrm{ml})$ followed by addition of $1 \mathrm{M} \mathrm{KO} t \mathrm{Bu}$ solution in $t \mathrm{BuOH}(4.5 \mathrm{ml})$ and stirred for $72 \mathrm{~h}$ in the dark. To this solution pyridine $(1.9 \mathrm{ml})$, EtOAc $(0.9 \mathrm{ml})$ and $\mathrm{CHCl}_{3}(10 \mathrm{ml})$ were added and the resulting mixture was then transferred to a separatory funnel with $\mathrm{H}_{2} \mathrm{O}(10 \mathrm{ml})$. The organic layer was separated, extracted with EtOAc $(15 \mathrm{ml})$, dried over $\mathrm{Na}_{2} \mathrm{SO}_{4}$ and evaporated. The dark brown residue was dissolved in $5 \% \mathrm{H}_{2} \mathrm{SO}_{4}$ in $\mathrm{MeOH}(15.7 \mathrm{ml})$ and stirred in the dark for $14 \mathrm{~h}$. The solution was diluted with $\mathrm{CH}_{2} \mathrm{Cl}_{2}(12 \mathrm{ml})$ and washed with $\mathrm{NaOAc}_{\text {(aq.) }}$ $(15 \mathrm{ml}), \mathrm{NaHCO}_{3 \text { (aq.) }}(15 \mathrm{ml})$ and finally brine $(10 \mathrm{ml})$. The organic layer was dried over $\mathrm{Na}_{2} \mathrm{SO}_{4}$, filtered and evaporated. The residue was purified by flash chromatography on silica gel with $\mathrm{CH}_{2} \mathrm{Cl}_{2}$ as the solvent (the column was covered with aluminum foil to limit exposure to light). Compound 7 was obtained as deep red needles (8.7 mg, $13.4 \mu \mathrm{mol}, 78 \%$ ).

Melting point $217-219^{\circ} \mathrm{C} . \quad R_{\mathrm{f}}=0.50 \quad\left(\mathrm{CH}_{2} \mathrm{Cl}_{2}\right) . \quad{ }^{1} \mathrm{H} \quad \mathrm{NMR}$ (400 MHz, $\mathrm{CDCl}_{3}$ ): $\delta 10.23$ (s, 1H), 10.16 (s, 1H), 10.09 (s, 1H), 10.07 (s, 1H), 8.29 (dd, $J=17.8,11.4 \mathrm{~Hz}, 1 \mathrm{H}), 6.34(\mathrm{~d}, J=17.7 \mathrm{~Hz}$, $1 \mathrm{H}), 6.17(\mathrm{~d}, J=11.3 \mathrm{~Hz}, 1 \mathrm{H}), 4.47-4.36\left(\mathrm{~m}, 4 \mathrm{H}, 2 \times \mathrm{CH}_{2}\right)$, $3.78-3.58$ (m, 9H, 3×OMe), 3.31-3.22 (m, 4H, $\left.2 \times \mathrm{CH}_{2}\right), 2.39-2.24$ (m, $\left.4 \mathrm{H}, 2 \times \mathrm{CH}_{2}\right), 1.50-1.40(\mathrm{~m}, 12 \mathrm{H}, 4 \times \mathrm{Me}),-3.68(\mathrm{~s}, 2 \mathrm{NH}) . \mathrm{HR}-$ ESI-MS: calcd. $\mathrm{C}_{38} \mathrm{H}_{43} \mathrm{~N}_{4} \mathrm{O}_{6}[\mathrm{M}+\mathrm{H}]^{+} 651.3183$, found 651.3182 .

\section{HPLC analysis}

Reaction products of HemN and HemF activity assays were analyzed by HPLC. Activity assays were performed as described above. For protein precipitation, $5 \mu \mathrm{l}$ of $\mathrm{HCl}(37 \% \mathrm{w} / \mathrm{v})$ was added to the $\mathrm{H}_{2} \mathrm{O}_{2}$ oxidized reaction mixtures and precipitated proteins were removed by centrifugation. The resulting supernatant $(100 \mu \mathrm{l})$ was mixed with $100 \mu \mathrm{l}$ of acetone/ $\mathrm{HCl}(97.5: 2.5 \mathrm{v} / \mathrm{v})$ and the sample was centrifuged for $3 \mathrm{~min}$. A $20-\mu \mathrm{l}$ aliquot of the resulting supernatant was loaded onto a $4.6 \times 250 \mathrm{~mm}$ Equisil BDS C18-2 reversephase column (Dr. Maisch GmbH, Ammerbuch, Germany; particle size $5 \mu \mathrm{m})$. Porphyrin separation was performed at a flow rate of $0.5 \mathrm{ml} / \mathrm{min}$ using $17 \%(\mathrm{v} / \mathrm{v})$ ammonium acetate $(1 \mathrm{M}, \mathrm{pH} 5.2)$ and $10 \%(\mathrm{v} / \mathrm{v})$ acetonitrile in methanol as mobile phase. Porphyrins were detected by fluorescence measurement using an excitation wavelength of $409 \mathrm{~nm}$ and an emission wavelength of $630 \mathrm{~nm}$ and in parallel by UV photometric diode array over the range $200-650 \mathrm{~nm}$. The HPLC system was a Jasco 1500 series (Jasco, Groß-Umstadt, 
Germany). Coproporphyrin III and protoporphyrin IX were used as porphyrin standards.

\section{Porphyrin extraction for mass spectrometry}

Porphyrins were extracted from activity assay mixtures as previously described using ethyl acetate/acetic acid (3:1 v/v) (Layer et al., 2006). In the final step of this procedure the porphyrins in the ethyl acetate/acetic acid fraction were extracted with $15 \%(\mathrm{w} / \mathrm{v})$ $\mathrm{HCl}$. The $\mathrm{pH}$ of this $\mathrm{HCl}$ solution was adjusted to 4.0 by addition of saturated sodium acetate solution to precipitate the porphyrins. After centrifugation the precipitated porphyrins were washed once with $\mathrm{H}_{2} \mathrm{O}$. The remaining porphyrin sediment after centrifugation was freeze-dried and stored at $-20^{\circ} \mathrm{C}$ until further use.

\section{Mass spectrometry}

LR-ESI-MS data were acquired on a Bruker Esquire instrument (Bruker Daltonik, Bremen, Germany). Samples were dissolved in methanol and introduced by direct infusion at a flow rate of $3 \mu \mathrm{l} /$ min. HR-ESI-MS data were recorded on a Micromass LCT instrument (Waters GmbH, Eschborn, Germany). HR-EI-MS measurements were performed on a Finnigan MAT 711 instrument (Finnigan MAT, Bremen, Germany). Data were obtained by peak matching at a resolution of approximately 10000 (10\% valley definition).

\section{NMR spectroscopy}

${ }^{1} \mathrm{H}$ NMR spectra were recorded on a Bruker DPX-200 or DPX-400 spectrometer (Bruker Analytische Messtechnik, Rheinstetten, Germany). ${ }^{13} \mathrm{C}$ NMR spectra were recorded on a Bruker AVS-400 instrument (Bruker Analytische Messtechnik). Deuterochloroform or tetramethylsilane was used as the internal standard.

\section{Acknowledgments}

We thank Prof. Jean-Charles Deybach and Caroline Schmitt (University of Paris VII, France) for the gift of plasmids pGEX-2T:CPO and pGEX-2T:CPO $(R 401 K)$. We would like to thank Prof. Dieter Jahn for continuous support and helpful discussions. This work was supported by grants from the Deutsche Forschungsgemeinschaft to D.W.H. and by the Emmy-Noether-Program of the Deutsche Forschungsgemeinschaft to G.L. Funds from the Fonds der Chemischen Industrie are gratefully acknowledged by G.L. and D.W.H.

\section{References}

Arsenault, G.P., Bullock, E., and MacDonald, S.F. (1960). Pyrromethanes and porphyrins therefrom. J. Am. Chem. Soc. 82, 4384-4389.

Breckau, D., Mahlitz, E., Sauerwald, A., Layer, G., and Jahn, D. (2003). Oxygen-dependent coproporphyrinogen III oxidase (HemF) from Escherichia coli is stimulated by manganese. J. Biol. Chem. 278, 46625-46631.

Carr, R.P., Jackson, A.H., Kenner, G.W., and Sach, G.S. (1971). Pyrroles and related compounds. Part XVI. Synthesis of protoporphyrin-IX by the $a$ - and $b$-oxobilane routes. J. Chem. Soc. C, 487-502.
Cavaleiro, J.A., Kenner, G.W., and Smith, K.M. (1973). Biosynthetic intermediates between coproporphyrinogen-III and protoporphyrinogen-IX. J. Chem. Soc. Chem. Commun. 5, 183-184.

Cavaleiro, J.A., Kenner, G.W., and Smith, K.M. (1974). Pyrroles and related compounds. XXXII. Biosynthesis of protoporphyrinIX from coproporphyrinogen-III. J. Chem. Soc. Perkin 1 10, 1188-1194.

Chen, Q., Huggins, M.T., Lightner, D.A., Norona, W., and McDonagh, A.F. (1999). Synthesis of a 10-oxo-bilirubin: effects of the oxo group on conformation, transhepatic transport, and glucuronidation J. Am. Chem. Soc. 121, 9253-9264.

Elder, G.H., Evans, J.O., Jackson, J.R., and Jackson, A.H. (1978). Factors determining the sequence of oxidative decarboxylation of the 2- and 4-propionate substituents of coproporphyrinogen III by coproporphyrinogen oxidase in rat liver. Biochem. J. 169, 215-223.

Falk, J.E., Dresel, E.I., Benson, A., and Knight, B.C. (1956). Studies on the biosynthesis of blood pigments. 4 . The nature of the porphyrins formed on incubation of chicken erythrocyte preparations with glycine, $\delta$-aminolaevulic acid or porphobilinogen. Biochem. J. 63, 87-94.

Games, D.E., Jackson, A.H., and Jackson, J.R. (1976). Biosynthesis of protoporphyrin-IX from coproporphyrin-III. J. Chem. Soc. Chem. Commun. 6, 187-188.

Heinemann, I.U., Jahn, M., and Jahn, D. (2008). The biochemistry of heme biosynthesis. Arch. Biochem. Biophys. 474, 238-251.

Lash, T.D., Mani, U.N., Drinan, M.A., Zhen, C., Hall, T., and Jones, M.A. (1999). Normal and abnormal heme biosynthesis. I. Synthesis and metabolism of di- and monocarboxylic porphyrinogens related to coproporphyrinogen-III and harderoporphyrinogen: a model for the active site of coproporphyrinogen oxidase. J. Org. Chem. 64, 464-477.

Layer, G., Verfürth, K., Mahlitz, E., and Jahn, D. (2002). Oxygenindependent coproporphyrinogen-III oxidase HemN from Escherichia coli. J. Biol. Chem. 277, 34136-34142.

Layer, G., Moser, J., Heinz, D.W., Jahn, D., and Schubert, W.D. (2003). Crystal structure of coproporphyrinogen III oxidase reveals cofactor geometry of radical SAM enzymes. EMBO J. 22, 6214-6224.

Layer, G., Grage, K., Teschner, T., Schünemann, V., Breckau, D., Masoumi, A., Jahn, M., Heathcote, P., Trautwein, A.X., and Jahn, D. (2005). Radical $S$-adenosylmethionine enzyme coproporphyrinogen III oxidase HemN: functional features of the [4Fe-4S] cluster and the two bound $S$-adenosyl-L-methionines. J. Biol. Chem. 280, 29038-29046.

Layer, G., Pierik, A.J., Trost, M., Rigby, S.E., Leech, H.K., Grage, K., Breckau, D., Astner, I., Jänsch, L., Heathcote, P., et al. (2006). The substrate radical of Escherichia coli oxygen-independent coproporphyrinogen III oxidase HemN. J. Biol. Chem. 281, 15727-15734.

Ludwig, J. and Lehr, M. (2004). Convenient synthesis of pyrroleand indolecarboxylic acid tert-butylesters. Syn. Commun. 34, 3691-3695.

Nordmann, Y., Grandchamp, B., de Verneuil, H., Phung, L., Cartigny, B., and Fontaine, G. (1983). Harderoporphyria: a variant hereditary coproporphyria. J. Clin. Invest. 72, 1139-1149.

Sano, S. and Granick, S. (1961). Mitochondrial coproporphyrinogen oxidase and protoporphyrin formation. J. Biol. Chem. 236, 11731180 .

Schmitt, C., Gouya, L., Malonova, E., Lamoril, J., Camadro, J.M., Flamme, M., Rose, C., Lyoumi, S., Da Silva, V., Boileau, C., et 
al. (2005). Mutations in human $C P O$ gene predict clinical expression of either hepatic hereditary coproporphyria or erythropoietic harderoporphyria. Hum. Mol. Genet. 14, 3089-3098.

Sofia, H.J., Chen, G., Hetzler, B.G., Reyes-Spindola, J.F., and Miller, N.E. (2001). Radical SAM, a novel protein superfamily linking unresolved steps in familiar biosynthetic pathways with radical mechanisms: functional characterization using new analysis and information visualization methods. Nucleic Acids Res. 29, 1097-1106.

Received September 4, 2009; accepted September 24, 2009 